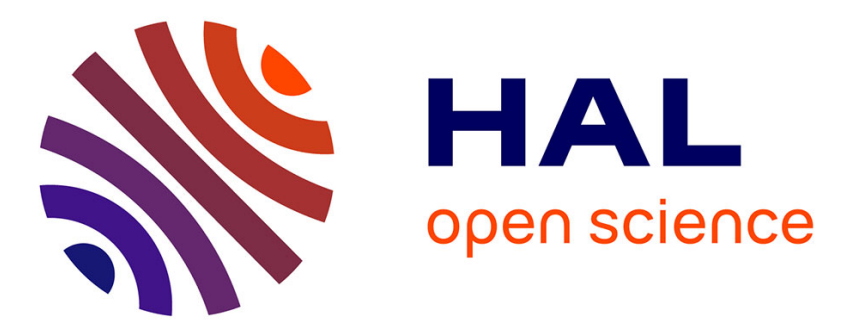

\title{
Analytical evaluation of Lumipulse® BRAHMS PCT CLEIA assay and clinical performances in an unselected population as compared with central lab PCT assay
} Anne Marie Dupuy, Maxence Né, Anne-Sophie Bargnoux, Stéphanie Badiou, Jean-Paul Cristol

\section{To cite this version:}

Anne Marie Dupuy, Maxence Né, Anne-Sophie Bargnoux, Stéphanie Badiou, Jean-Paul Cristol. Analytical evaluation of Lumipulse ${ }^{\circledR}$ BRAHMS PCT CLEIA assay and clinical performances in an unselected population as compared with central lab PCT assay. Clinical Biochemistry, 2017, 50 (4-5), pp.248 - 250. 10.1016/j.clinbiochem.2016.11.006 . hal-01801582

\section{HAL Id: hal-01801582 \\ https://hal.umontpellier.fr/hal-01801582}

Submitted on 27 Jan 2020

HAL is a multi-disciplinary open access archive for the deposit and dissemination of scientific research documents, whether they are published or not. The documents may come from teaching and research institutions in France or abroad, or from public or private research centers.
L'archive ouverte pluridisciplinaire HAL, est destinée au dépôt et à la diffusion de documents scientifiques de niveau recherche, publiés ou non, émanant des établissements d'enseignement et de recherche français ou étrangers, des laboratoires publics ou privés. 


\title{
Analytical evaluation of Lumipulse® BRAHMS PCT CLEIA assay and clinical performances in an unselected population as compared with central lab PCT assay
}

\author{
Anne Marie Dupuy ${ }^{a}$, Maxence Né ${ }^{a}$, Anne Sophie Bargnoux ${ }^{\mathrm{a}, \mathrm{b}}$, Stéphanie Badiou ${ }^{\mathrm{a}, \mathrm{b}}$, Jean Paul Cristol ${ }^{\mathrm{a}, \mathrm{b}, *}$ \\ ${ }^{a}$ Department of Biochemistry, Centre Ressources Biologiques de Montpellier, University Hospital of Montpellier, Montpellier, France \\ b PhyMedExp, University of Montpellier, INSERM U1046, CNRS UMR 9214, 34295 Montpellier cédex 5, France
}

Keywords:

PCT

Sensitivity

Specificity

Clinical concordance

\section{A B S T R A C T}

Objectives: We report the analytical performances of the Lumipulse®G BRAHMS PCT assay (Fujirebio, Courteboeuf, France) and the concordance with BRAHMS PCT Kryptor CompactPlus@ results from central laboratory.

Design and methods: Lumipulse ${ }^{\circledR} G$ BRAHMS PCT immunoassay on Lumipulse ${ }^{\circledR} G 600 I$ instrument is a chemiluminescence enzyme immunoassay (CLEIA). Analytical performances included imprecision study, linearity, limit of detection and comparison study on 138 plasma specimen on Lumipulse ${ }$ G600II vs plasma on Kryptor CompactPlus $\mathfrak{C}$.

Results: The intra and inter assay imprecision of Lumipulse ${ }^{\circledR}$ G BRAHMS PCT was between 2 and $5 \%$. The LoD in our condition was $0.0029 \mathrm{ng} / \mathrm{mL}$ in accordance with the LoD provided by the manufacturer $(0.0048 \mathrm{ng} / \mathrm{mL})$. The linear equation of linearity was $\mathrm{y}=1,001 \times-0,052$ with $\mathrm{r}^{2}=0.99$, with a mean recovery (SD) percentage of $1.8 \%$ (8\%). Correlation studies showed a good correlation $(r=0.99)$ between plasma on Kryptor and Lumipulse, with a bias of 0.02 in the range from 0.12 to $1 \mathrm{ng} / \mathrm{mL}$.

Conclusion: The new adaptation developed from Fujirebio on quantification of PCT with CLEIA technology from monoclonal antibodies from ThermoFisher appears to be acceptable for clinical use.

\section{Introduction}

The demand for routine measurement of PCT has consistently increased during the last decade in clinical laboratories. PCT indications cover a large broad of clinical situations from emergency departments to specialized medical units. PCT is well established as a biomarker that reflects the presence and severity of local and systemic bacterial infections, i.e., sepsis [1]. More recently, it has been shown that PCT is a valuable tool to guide antibiotic treatment in patients with bacterial infections [2-4] allowing to tailor antibiotic treatment and to reduce antibiotic resistance [5]. PCT is widely used as rule out test for sepsis and it is frequently requested by primary care doctors facilitating clinician decision. Several studies have shown that the prognosis depends on the rapidity of specific treatment, which should ideally be initiated within four hours and no later than eight hours after diagnosis [6-7].

\footnotetext{
* Corresponding author at: Department of Biochemistry, University Hospital of Montpellier, Montpellier, France.

E-mail address: jp-cristol@chu-montpellier.fr (J.P. Cristol).
}

The original reference was the method BRAHMS PCT Kryptor@ assay. In recent years, companies have two approaches, either to produce their own antibodies since PCT's patent expired and came into the public domain (as Diazyme or Radiometer), or adapt the BRAHMS antibodies on their instrument.

In the later case, several manufacturers (Roche, Siemens, Diasorin, Abbott...) have adapted on their instruments the determination of PCT from reagent provided by Brahms, leading a faster turnaround time and a real laboratory consolidation. The assays methods were therefore diverse including electro-chimiluminescence method (ECLIA), enzyme-linked fluorescence, chemiluminescence while the measurement principle of BRAHMS KRYPTOR CompactPlus ( is based on Time-resolved amplified cryptate emission (TRACE Technology). In this area too, Fujirebio launched the determination of PCT based on chemiluminescent enzyme immunoassay (CLEIA) technology on their immunoassay systems. Here, we report the analytical performances of the Lumipulse ${ }^{\circledR} G$ BRAHMS PCT assay (Courteboeuf, France) and we evaluate the concordance with BRAHMS PCT Kryptor CompactPlus@ results from central laboratory. 


\section{Materials and methods}

\subsection{Lumipulse@ G BRAHMS PCT method}

Lumipluse (C) G BRAHMS PCT assay on Lumipulse(C G600II system instrument is a one step sandwich based on CLEIA technology. Reagents, calibrators, controls were provided by ThermoFisher using two antiPCT monoclonal antibodies. The minimum sample volume is $250 \mu \mathrm{L}$. Dry tube or plasma collected in sodium heparin, lithium heparin, dipotassium EDTA, disodium EDTA or sodium citrate anticoagulant tubes are acceptable. Results were obtained within $35 \mathrm{~min}$. The 95th percentile was to be $<0.16 \mathrm{ng} / \mathrm{mL}$. Reagents, calibrators, and controls were used according to the manufacturers' recommendations with an analytic measuring range up to $100 \mathrm{ng} / \mathrm{mL}$.

\subsection{PCT central laboratory method}

At central laboratory, the measurement principle of BRAHMS PCT assay is based on TRACE (Time Resolved Amplified Cryptate Emission) on Kryptor Compact Plus $₫$ instrument (ThermoScientific, BRAHMS AG, Hennigsdorf, Germany) using anti-calcitonin polyclonal antibody conjugated with europium cryptate and anti-katacalcin monoclonal antibody conjugated with XL665. Results were obtained within 19 min on the Kryptor ${ }^{\circledR}$ system. The 95th percentile was to be $<0.064 \mathrm{ng} / \mathrm{mL}$.

\subsection{Analytical performances of Lumipulse ${ }^{\circledR} G$ BRAHMS PCT immunoassay}

Imprecision studies were based on the CLSI EP5 protocol (duplicate measurements twice per day on 3 levels for 20 consecutive days) [8] from heparinized plasma pools and control materials ready to use. The limit of detection (LoD) and the limit of quantification (LoQ) were determined according to the current CLSI standard [9]. An heparinized plasma pool with PCT concentration of $5.7 \mathrm{ng} / \mathrm{mL}$ was used to test the linearity. The pool was diluted at the following final concentrations: $1.9,0.9,0.48,0.24,0.12,0.06$ and $0.03 \mathrm{ng} / \mathrm{mL}$. Each concentration was measured in duplicate.

The comparison study was based on samples obtained from 138 consecutive patients admitted to the emergency department (ED) and the Unit Intensive Care departments of Lapeyronie university hospital (Montpellier, France) covering the analytical range of $0.02-50 \mathrm{ng} / \mathrm{mL}$, per the reference method (BRAHMS PCT Kryptor CompactPlus@). Testing was performed simultaneously measuring the PCT from heparinized plasma on the Kryptor Compact Plus@ instrument and on the Lumipulse@G600II instrument. The residual samples were used to method comparison. Only BRAHMS PCT Kryptor CompactPlus@ values were used for the clinical diagnosis.

\subsection{Statistical analysis}

Passing-Bablok regression analysis was used to compare results of Lumipulse@G BRAHMS PCT assay with the BRAHMS PCT Kryptor@ method on Kryptor Compact Plus® used in our daily practice. In addition, the scatter of differences was visualized by means of BlandAltman plots [10]. Statistical analyses were performed using XLSTAT ${ }^{\circledR}$ software, version 2016.06.35661 (NY, USA).

In addition, to better evaluate the concordance between methods, the population was divided into 3 categories as follows: category 1 , PCT values $<0.5 \mathrm{ng} / \mathrm{mL}$; category 2 , PCT between 0.5 and $2 \mathrm{ng} / \mathrm{mL}$; and category 3 , PCT with values $\geq 2 \mathrm{ng} / \mathrm{mL}$. Clinical concordance between the methods with disease state samples was then assessed using Cohen's $\kappa$-test [11]. Values $<0.40$ indicate low association; values between 0.40 and 0.75 indicate medium association; and values $>0.75$ indicate high association. For all comparisons, p-value $<0.05$ was considered statistically significant. In the presence of discordant results between two methods, the samples were re-analyzed on the two instruments and the clinical record was checked.

\section{Results and discussion}

Results of imprecision study are presented in Table 1 . The within-run $\mathrm{CV}$ gave satisfactory results (all $\mathrm{CVs}<3.0 \%$ ). The total precision $\mathrm{CV}$ ranged from $5.0 \%$ for the lowest concentration to $3.0 \%$ for the highest. These levels of imprecision were comparable with those reported for the PCT assay on the BRAHMS Kryptor CompactPlus $\subset$ claimed by the manufacturer. CVs showed excellent analytical performances with all CVs $<5 \%$. The LoD in our condition was $0.0029 \mathrm{ng} / \mathrm{mL}$ in accordance with the LoD provided by the manufacturer $(0.0048 \mathrm{ng} / \mathrm{mL})$. The LoQ was $0.0059 \mathrm{ng} / \mathrm{mL}$ lower than that given by the manufacturer $(0.0079 \mathrm{ng} / \mathrm{mL})$. The linear equation of linearity was $y=1,001 \times-0,052$ with $r^{2}=0.99$, with a mean recovery (SD) percentage of $91.8 \%(8 \%)$.

Fig. 1 shows the regression analysis of the 138 values of PCT obtained from plasma samples on Lumipulse $\subset$ C $G$ analyzer vs plasma on Kryptor Compact Plus $\mathbb{C}$. The correlation coefficient of the linear regression was $\mathrm{r}=0.99$ (Lumipulse $C \mathrm{CG}=1,07$ Kryptor Compact Plus $(\mathrm{C}+0,0447$ ), with a slight overestimation of the Fujirebio assay, indicating that the assay method exhibited good correlation in the working range of $0.12-50 \mathrm{ng} / \mathrm{mL}$. Results of Bland-Altman analyses on the overall samples demonstrated an acceptable concordance with a bias of $0.42( \pm$ 1.27)ng/mL. Bland-Altman plot seems to show an increased difference between the two methods with increasing levels of PCT. The points out of the $1.96 \pm$ SD limit line are for the values above $10 \mathrm{ng} / \mathrm{mL}$. The cut-off of $0.5 \mathrm{ng} / \mathrm{mL}$ is the most used and allows differentiating systemic infection suggestive of sepsis from sterile causes of severe systemic inflammation [4]. In consequence, we took a closer look around this threshold. In the range from 0.12 to $1 \mathrm{ng} / \mathrm{mL}(\mathrm{n}=70)$, the regression analysis showed a correlation coefficient of 0.96 and slope of 1.15 with an intercept of -0.03 . Bland-Altman analysis confirmed the excellent agreement between the two methods at low PCT concentrations (mean difference $0.02+0.08 \mathrm{ng} / \mathrm{mL}$ ) with 2 points out of the $1.96 \pm$ SD limit line.

Only 2 (i.e. $1.44 \%$ ) and 6 (i.e. $4.4 \%$ ) results disagreed between Lumipulse@G with the categories 1 and 2 assignment of BRAHMS Kryptor CompactPlus(C) assay, respectively. However, values for the 2 discordants ( 1 patient with diabetic ketoacidosis and 1 renal transplant patient) of the area $0.5 \mathrm{ng} / \mathrm{mL}$ were close (sample $1: 0.46 \mathrm{vs} 0.53$, sample 2: 0.50 vs 0.40 for Kryptor CompactPlus@ vs Lumipulse®G, respectively). It was the same for sample values of the area around $2 \mathrm{ng} / \mathrm{mL}$ The diagnoses of these 6 patients were: 1 patient with ventilatorassociated pneumonia, 2 liver transplant patients, 1 patient with pneumococcal meningitis, 1 patient with pneumonia due to morphine overdose and 1 patient with sepsis. PCT-Kryptor values for these 6 patients were between 1.03 and $2.08 \mathrm{ng} / \mathrm{mL}$, and PCT- Lumipulse values were between 1.87 and $2.30 \mathrm{ng} / \mathrm{mL}$. The discrepancies between the methods have no impact on clinical care of patients.

In this context, the Kappa coefficients was close to 0.94 and consequently the strength of agreement is considered to be very good between Lumipulse ${ }^{\circledR} G$ BRAHMS PCT assay and BRAHMS Kryptor CompactPlus@ assay. Globally, the figures indicated that the difference was minimal without risk to the patient. As regards the correlation with PCT Kryptor CompactPlus@, Lumipulse@C BRAHMS PCT exhibit a

Table 1

Analytical characteristics of Lumipulse $\subset$ G BRAHMS PCT assay on Lumipulse® G600II instrument from Fujirebio.

\begin{tabular}{llll}
\hline Total CV imprecision results & Mean $(\mathrm{ng} / \mathrm{mL})$ & $\mathrm{SD}(\mathrm{ng} / \mathrm{mL})$ & $\mathrm{CV}(\%)$ \\
\hline Plasma pool & 0,06 & 0,003 & 5,18 \\
Plasma pool & 0,32 & 0,007 & 2,09 \\
Control level 1 & 0,80 & 0,0019 & 2,29 \\
Control level 2 & 16,71 & 0,516 & 3,09 \\
Linearity & Mean recovery $(\%)$ & SD\% & \\
& 91,8 & 8,07 & \\
\hline
\end{tabular}

$\mathrm{CV}$, coefficient of variation; SD, standard deviation. 
(A)

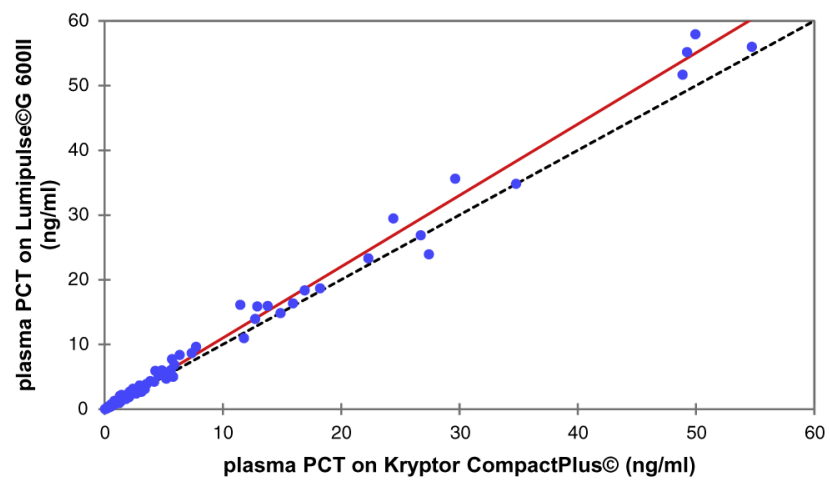

(B)

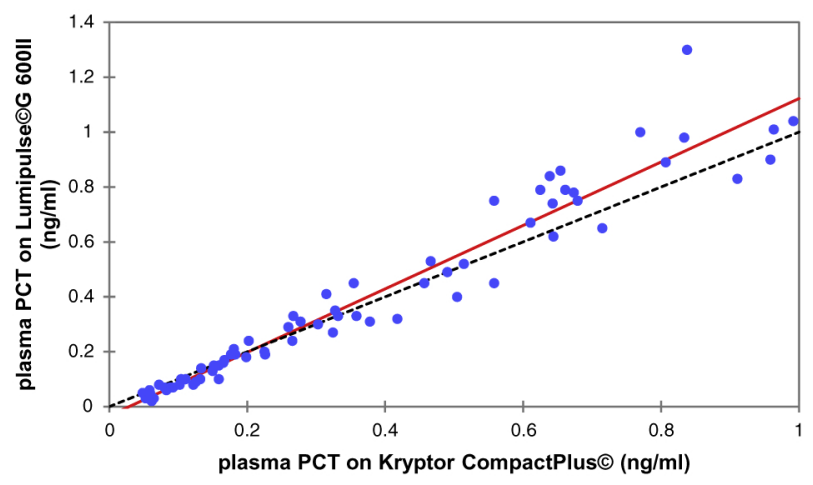

(C)

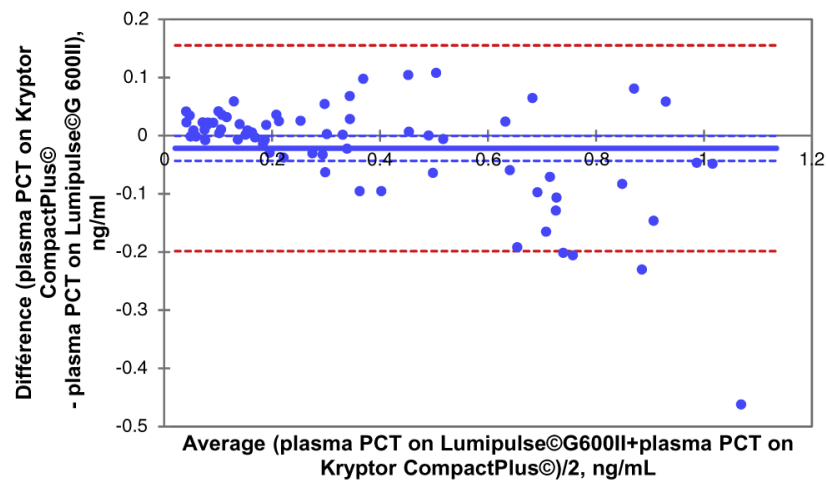

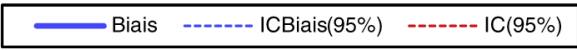

Fig. 1. Passing-Bablok regression analysis of PCT-Lumipulse@ G600II against PCT-BRAHMS Kryptor CompactPlus@ on plasma sample, (A) on all samples, $\mathrm{Y}=1.102 \times-0.026 ; \mathrm{n}=$ 138 , slope $1.102(1.06-1.13)$, intercept $-0.026(-0.038-0.013)(B)$ in the range from 0.12 to $1 \mathrm{ng} / \mathrm{mL}, \mathrm{y}=1.155 \times-0.033, \mathrm{n}=70$, slope 1.155 (1.081-1.226), intercept $-0.033(0.045-0.019)$ and (C) Bland-Altman difference plots on PCT results in the range from 0.12 to $1 \mathrm{ng} / \mathrm{mL}$ (bias $-0.022,+1.96 \mathrm{SD}=0.15,-1.96 \mathrm{SD}=-0.19$ ). good agreement in a range of levels between 0.1 and $50 \mathrm{ng} / \mathrm{mL}$ and especially in the critical area around $0.5 \mathrm{ng} / \mathrm{mL}$.

In conclusion, the new adaptation developed from Fujirebio on quantification of PCT by CLEIA technology from monoclonal antibodies provided by Brahms/ThermoFisher appears to be acceptable for clinical use. At our knowledge it was the first evaluation study in comparison with the established method on the Brahms Kryptor CompactPlus@ $\subseteq$. The Lumipulse ${ }^{\circ}$ BRAHMS PCT assay demonstrated excellent precision at the different cut-off studied. In addition, this PCT assay showed good agreement with the BRAHMS PCT Kryptor CompactPlus $\odot$ across the clinical measurement range, particularly at low concentrations.

\section{Conflicts of interest}

The authors declare that they have no conflict of interest.

\section{Acknowledgments}

The PCT reagents used in this study were provided by Fujirebio France.

\section{References}

[1] M. Assicot, D. Gendrel, H. Carsin, J. Raymond, J. Guilbaud, C. Bohuon, High serum procalcitonin concentrations in patients with sepsis and infection, Lancet 341 (1993) 515-518.

[2] P. Schuetz, W. Albrich, B. Mueller, Procalcitonin for diagnosis of infection and guide to antibiotic decisions: past, present and future, BMC Med. 9 (2011) 107.

[3] P. Schuetz, W. Albrich, M. Christ-Crain, J. Chastre, B. Mueller, Procalcitonin for guidance of antibiotic therapy, Expert Rev. Anti Infect. Ther. 8 (2010) 575-587.

[4] J.P. Quenot, C.E. Luyt, N. Roche, M. Chalumeau, P.E. Charles, Y.E. Claessens, et al., Role of biomarkers in the management of antibiotic therapy: an expert panel review II: clinical use of biomarkers for initiation or discontinuation of antibiotic therapy, Ann. Intensive Care 8 (2013).

[5] J. Davies, Procalcitonin, J. Clin. Pathol. 68 (2015) 675-679.

[6] T.P. Meehan, M.J. Fine, H.M. Krumholz, J.D. Scinto, D.H. Galusha, J.T. Mockalis, et al., Quality of care, process, and outcomes in Elderly patients with pneumonia, JAMA 278 (1997) 2080-2084.

[7] P.E. Marik, The clinical features of severe community-acquired pneumonia presenting as septic shock, J. Crit. Care 15 (2000) 85-90.

[8] CLSI, EP05, evaluation of precision performance of clinical chemistry devices; approved guideline, NCCLS Document EP5-a, CLSI, Wayne (PA), 1992.

[9] CLSI, EP17-A, Protocols for Determination of Limits of Detection and Limits of Quantitation, Clinical and Laboratory Standards Institute, Wayne, PA, 2004.

[10] J.M. Bland, D.G. Altman, Measuring agreement in method comparison studies, Stat. Methods Med. Res. 8 (1999) 135-160.

[11] I. Guggenmoos-Holzman, The meaning of kappa: probabilistic concepts of reliability andvalidity revisited, J. Clin. Epidemiol. 49 (1996) 775-782. 